\title{
SUSTAINABLE DEVELOPMENT OF E-LEARNING MATERIAL FOR OPENGIS STANDARDS
}

Robert Kaden, Gerhard König

Institute for Geodesy and Geoinformation Science, TU Berlin, Germany

robert.kaden@tu-berlin.de,gerhard.koenig@tu-berlin.de

Commission VI, WG VI/2

KEY WORDS: Education, E-Learning, M-Learning, Teaching, Mobile Device, Podcast, CityGML

\begin{abstract}
:
In this paper we discuss our experiences in creating lectures-on-demand using Flash streams based on MS PowerPoint slides that are enriched by author's comments (audio as well as video streams). We depict the drawbacks concerning up-to-dateness of lecture content and compatibility with different desktop and mobile devices. According to this, we focus on our workflow to create lectures using podcasts including slides, animations and movies that is independent from the lecturers' presence. In contrast to podcasts recording classroom lectures, we propose to store authors' explanations as text and to add his comments to the learning material in synthetic voice. Out-dated material can be exchanged without creating new video sequences in lecture time and extent and avoids time consuming re-taping and editing of existing course content. Moreover, splitting learning modules into small pieces facilitates and accelerates work during the regular update process. With this approach we are able to improve sustainability, since it saves cost and allows just in time production of rapidly changing learning content.
\end{abstract}

\section{INTRODUCTION}

The establishment of mass applications like Google Maps, Bing Maps, etc. has been increasing the demand and the distribution of geoinformation over the last decade. Furthermore, the development of simulation and analytical tools requires more intelligent urban models with rich thematically representation of the environment. Along with this movement, a strong open source community forced the development of open standards for the management and exchange of geodata. Using open standards allows structurally and semantically data compatibility in terms of geodata infrastructures and support the integration of geodata. The Open Geospatial Consortium (OGC) has been released a number of important and established standards like GML, CityGML, WMS, etc., which are applied by a fast growing number of applications and users in the scientific, commercial, and governmental sector. The Institute of Geodesy and Geoinformation Science (IGG) at the Technische Universität Berlin has made substantial contributions to the development of standards in the OGC, especially to the encoding standard „OpenGIS City Geography Markup Language (CityGML)“ (Open Geospatial Consortium, 2008).

Against this background we have perceived an increasing demand on learning material providing depictive explanations and examples of those standards and its usage instead of reading the extensive but often tedious encoding documentation. This is true for people in education and business likewise as such learning material enforces motivation and comprehensibility and thereby leads to saving time. The IGG has developed multimedia e-learning material including lectures-on-demand, exercises, and podcasts to give people an understanding of urban information modelling, GML, and CityGML. However, the on-going process of the development of standards leads to incidental changes of the lecture material concerning releases and versions, content, etc. - a challenge for module developers to keep learning material up-to-date.

\subsection{Urban Information Modelling}

Virtual 3D city models gain more and more importance in science, government, and private industry. For visualization and navigation purposes, only graphic and geometric information is needed. But the increasing number of more complex applications and objectives require more sophisticated models.

The intention of Urban Modelling is to create a computer representation of the objects and characteristics of an urban terrain including natural and man-made features relevant to specific application fields. Key properties are spatial, graphical, and thematic information about the entities in and around cities providing information on the location, shape, extent, visual appearance, classification, thematic attributes, and their interrelationships.

Different applications and use cases have different requirements on the resolution and level of detail of the objects of an urban model and their modelled aspects. For example, for the visual inspection of the urban topography by an operator it will be sufficient to represent the geometry and graphical appearance of the urban terrain. If thematic or spatio-thematic queries and analyses should be carried out, like "list all windows of all buildings which have a line-ofsight to a specific place or route" also thematic information has to be represented, because computer algorithms must be able to distinguish between objects (in this case buildings), their parts (windows), and their location and orientation with respect to an object of interest (place or route).

\subsection{CityGML - an Application Schema of GML}

CityGML is an international standard for the representation and exchange of semantic 3D city and landscape models issued by the Open Geospatial Consortium (OGC). CityGML defines a common information model and data exchange format for $3 \mathrm{D}$ urban and rural objects. It specifies the classes and relations for the most relevant topographic objects in cities and regional models with respect to their geometrical, topological, semantic and appearance properties. Included are 
generalization hierarchies between thematic classes, and aggregation and thematic relations between objects. This thematic information goes beyond VR / CG standards and is required for sophisticated analysis tasks in different application domains like simulations, urban data mining, facility management, and thematic inquiries. CityGML is implemented as an application schema of the Geography Markup Language 3.1.1, the extensible international standard for geodata exchange and encoding issued by the OGC and the ISO TC211. It is further based on a number of standards from the ISO 191xx family, the OGC, the W3C Consortium, the Web 3D Consortium, and OASIS.

\section{DESKTOP BASED TRAINING COURSE}

In order to satisfy the demand on information about urban modelling, GML and CityGML, a desktop e-learning course on CityGML has been developed at the Technische Universität Berlin. The initiative to setup the course was pushed by the EuroSDR committee who decided to offer online training during the sixth and seventh round of annual courses. After successful training the course was slightly modified to be available to the public. This concerns the lack of tutorial assistance, which gave additional benefit to EuroSDR course subscriber.

\subsection{Concept}

Today's participants can consolidate their knowledge following lectures based on PowerPoint slides, which are enriched by video sequences and recorded as Adobe Flash videos. They form self-contained units, so called lectures-ondemand. Using an Internet browser allows listening to the teacher giving his speech, along with synchronized images of his presentation slides and all the animations, annotations, and comments. Slides can be identified using thumbnails or keywords, allowing individual repetitions during the followup work. Exercises complete the training workflow.

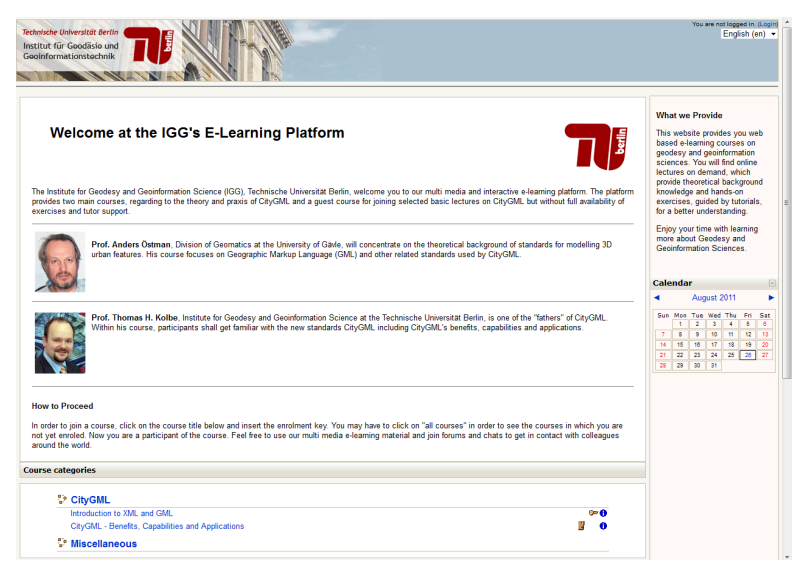

Figure 1: E-Learning platform of IGG http://www.igg.tu-berlin.de/courses

\subsection{Lectures-on-Demand}

As mentioned before, lectures-on-demand form separate units, based on PowerPoint. The Storyboard, the temporal operational sequence of the lecture, was modelled first as user-defined animation schema in PowerPoint. Corresponding audio/video sequences were recorded separately for each slide and carefully synchronised with the slide animations and -transitions. This material was converted with the help of the commercial program iSpring Ultra in Flash animations with ActionScript API, in order to produce a stream-compliant lecture-on-demand.

Figure 2 illustrates and summarises the workflow of lectureson-demand generation.

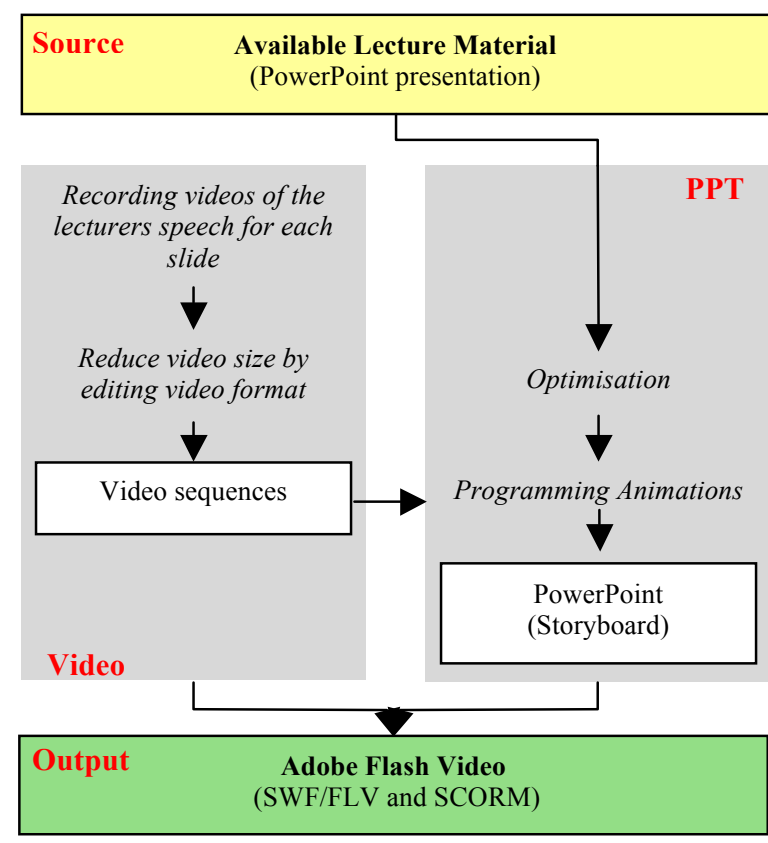

Figure 2: Flowchart of creating Lectures-on-Demand

When you start the lectures-on-demand, the audio-visual enriched PowerPoint slides appear on the screen. The following illustration (figure 3) identifies each part of the screen. Of course, the interaction potential can be only suggested here.

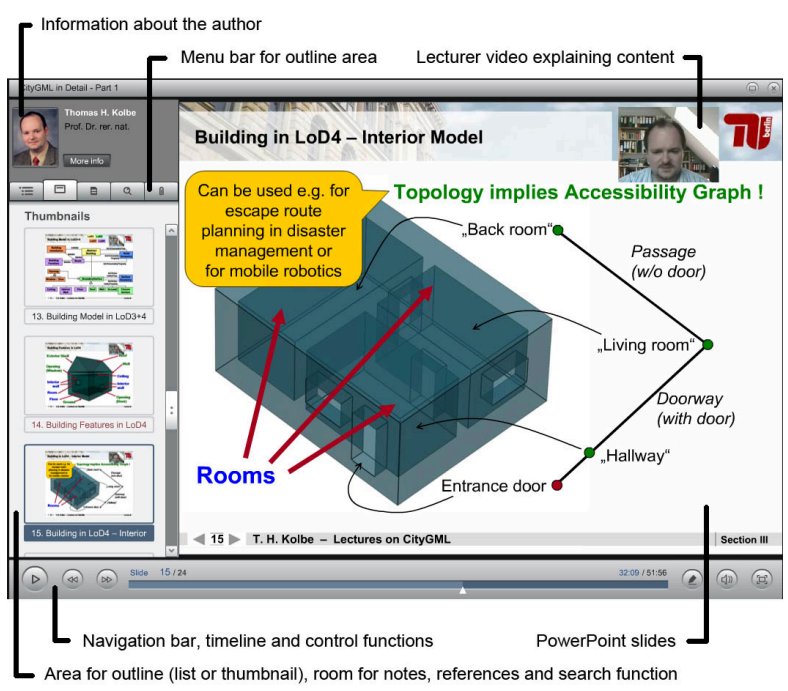

Figure 3: Lecture-on-demand screen layout

The outline area on the left gives an overview on contents discussed in this lecture. Slides can be identified in a list or as thumbnail that supports navigation graphically (figure 4a). By clicking on the desired topic the participant navigates directly to this slide. A search function facilitates content access by key words (figure $4 \mathrm{~b}$ ). At slide bottom one finds the usual control functions such as timeline, volume control etc. 
Main aims of the new development are

- making use of a higher degree of automation

- using text files that are transformed to synthetic speech

- focussing on mobile devices

- introducing podcasts to gain sustainability

\subsection{Moving to Mobile Learning}

The use of mobile devices has seen explosive growth within the last decades. Today's students grow up with innovative technologies. MP3 players and mobile phones have widespread acceptance. Students are confident technology users, and we think, that making use of mobile devices could enhance students' engagement, increase motivation and assist active and independent learning at own pace. Using the hype around portable devices and especially iPod, iPhone, and $\mathrm{iPad}$, which fascinate the young generation, we decided stepping into the students' world and complete the learning content by supporting these devices.

\section{TECHNICAL APPROACH}

The lessons learned led us following new paths. Podcasting is the appropriate technique to bring learning material, anytime and anywhere, to the user's mobile devices. Beside a browser or a simple and free podcatcher program (iTunes by Apple seems to be the most popular one, available for Windows and Mac OS) podcasts do not need any specific software or licence. Moreover, once downloaded podcasts are independent from Internet connections and can be played offline, anywhere and any often.

Not only the consumption of podcasts, but also the creation is quite easy. Three elements are required, the podcast (media file) itself, a RSS feed and a publication platform.

\subsection{Media Files}

One of the most important issues to produce a podcast is to choose an appropriate audio or video format. The main problem is to keep a reasonable file size, which strongly depends on the used codec, the frame size, bit rate etc. Optimisation of these parameters is of significant importance in order to minimise the download time, needed web space and traffic amount for the web server and for users with Internet transfer or time limits.

To be compatible with the wide variety of relevant handheld devices, we suggest choosing the MP3 audio format and MP4 video format, which is explained in König, Kaden, Kolbe (2010).

\subsection{Methods for Creating Video Podcasts}

Many e-learning podcasts available in the Internet are videotaped lectures, held during regular semester classes. This method is an easy and fast way to produce video podcasts, which is sufficient for presenting learning material with content that does not change significantly within short periods. No complex software, hardware and skills are needed, except an ordinary camcorder and free video software for cutting and storing the video with adequate format and size. The Photogrammetric Department at the University of Stuttgart successfully introduced this method in our fields and presented their experience during the
Photogrammetric Week 2007 (Fritsch 2007). Videotaped lectures are feasible to aid own students, especially during the recapitulation phase for examinations, as the podcast content is identical to the course subject. However, this method might not be the best way to prepare learning material for external participants for two reasons. The recorded video podcast could contain errors, which should have to be corrected, and secondly the lecture may base on a certain state of preknowledge that could not be presumed.

Another drawback is the lack of sustainability. Development dependent changes of content probably do not occur often in case of teaching fundamentals but are common in state-ofthe-art of science and technology. In the case of standardisation in geodata modelling, a lot of modifications have been occurring during the last years, especially concerning ISO and OGC standards as well as CityGML versions and data models. Presently CityGML version 1.1 will pass the standardisation procedure, which means that the course content needs to be updated again. Therefore, either the whole lecture has to be re-taped or one has to cut the video and re-tape at least the out-dated scenes. In the first case, it denotes to us to re-tape about six hours of lectures and in the second case it is necessary to bring the same lecturer to re-tape the updated parts in the similar environment.

We considered both ways for producing the updated lecture videos and deliberated which one is the most applicable and effective with respect to time requirement for producing the movie, occurring costs and assuring. But since both procedures require a lot of time and manpower, we aim for a further approach that is independent of a certain lecturer, the classroom environment and the real time scale for the production. Small changes like the declaration of a product version shall be done with a few mouse clicks, in few minutes.

\subsection{Creating Sustainable Course Content}

If a new learning course is started from scratch appropriate slides and videos have to be developed. In order to avoid double work the input can be derived from our university courses that are our day-to-day business. The videos for the mobile podcasts base on PowerPoint slides, which are presented in our class. In the first step we record the real lecture followed by transforming the spoken word into a written script automatically.

A variety of different Speech-to-Text programs is on the market, but our tests resulted in limited success. Main problems are background noise, subject-specific vocabulary and (probably) an insufficient training period, which complicates successful speech recognition. At present, using Dragons Naturally Speaking gives reasonable results but of course it is not perfect. In a second step manual text editing and revising is necessary. Once the text is available as script it is open for corrections with regard to contents, but also and this is a major advantage - for future modifications.

The video track based on PowerPoint slides can be produced quite easily. PowerPoint features include slide timing, slide animation and slide transition, which allows creating selfrunning presentations, similar to a video. For producing an ambiance of a lecture, at least the speech of a lecturer needs to be appended. To be as flexible as announced, we decided to replace the human speech by a synthetic voice. Speech synthesis requires well-formed scripts for conversion into audio tracks by text-to-speech technologies. The capabilities 
of these technologies have made a significantly step during the last years so that synthetic voices sounds impressively good. Many vendors of Text to Speech (TTS) solutions can be found, but with big differences in linguistic quality of sound, fluency, accentuation, and intonation. Suitable TTS software is not available for free and depending on quality, there are big differences in price. After extensive tests, we choose Adobe Captivate (version 4).

Figure 8 illustrates and summarises the workflow of podcast generation we propose.

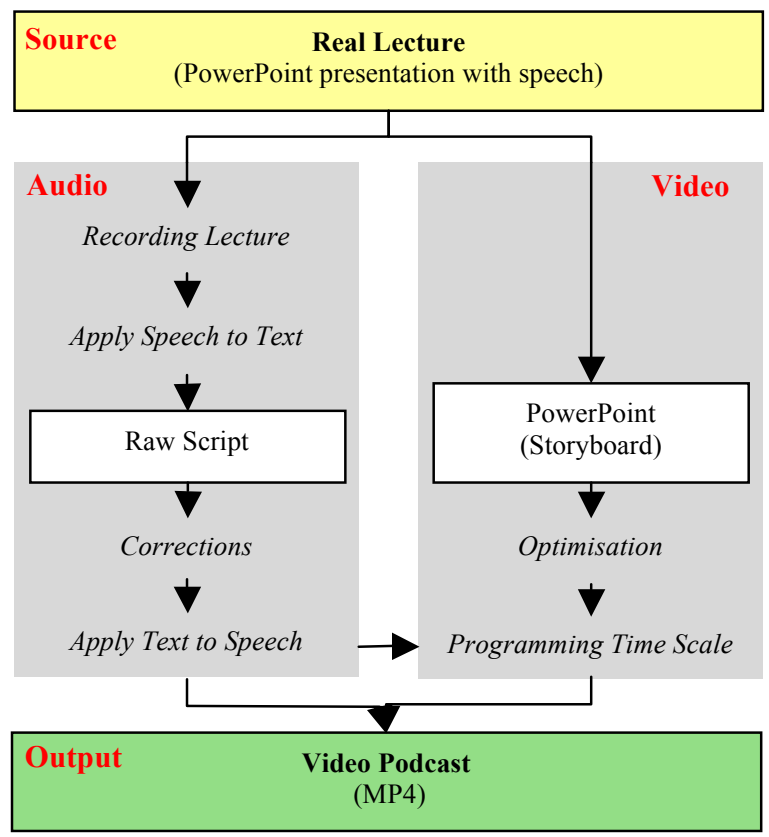

Figure 8: Flowchart of creating video podcasts

The next steps can be handled nearly automatically: besides TTS conversion, Adobe Captivate enables import and use of the prepared PowerPoint slides, synchronisation with the TTS audio tracks and export as an AVI video file. As our podcast should be compliant with the most common mobile devices, we decided to produce MP4 files. We used the open source Video to iPod Converter 3.3.6.81 to generate an optimised MP4 podcast video.

\subsection{RSS Feeds}

Really Simple Syndication (RSS) is a very important element for the success of podcasts as it describes the content and location of files in the Internet. Since one has subscribed the RSS feed, the user will get automatically updated files and new content. This is a big step towards sustainability, since students are informed directly if changes occur.

A RSS feed is stored as text file, consisting of tags for web syndication, which are specified using standardised XML. It contains metadata like authorship, a summery describing the audio or video podcast and especially the publishing date. Further information contain the web address (URL), the file size and the file type of the media document. That means, the podcast file itself is not physically connected to the RSS feed, and can be located anywhere on the Internet.

To obtain a podcast, users only need to subscribe the RSS feeds of interest. As explained before, subscribed feeds are checked regularly for new items and are downloaded automatically.

\subsection{Publication}

For publishing a podcast, the corresponding RSS feed needs to be located on a server with a public URL address. In the field of higher education, two target groups can be distinguished which allow two different ways for publishing. If a video podcast is addressed to students for internal use who intend to recapitulate the lectures, it might be enough to publish the RSS feed on local Internet pages or in a Learning Management Systems. If the learning material targets to customers worldwide, the RSS feed should use the service of noted portals like podcast.de, Apples iTunes Store or $i T u n e s U$. Beyond public visibility, well-known portals offer advanced search functions allowing RSS feeds to be filtered according to specific keywords, which is another main advantage.

Interested user will find our podcasts on the webpages of the institute: http://www.igg.tu-berlin.de/podcasts/rss.xml, as well as iTunes and podcast.de platforms (figure 9).

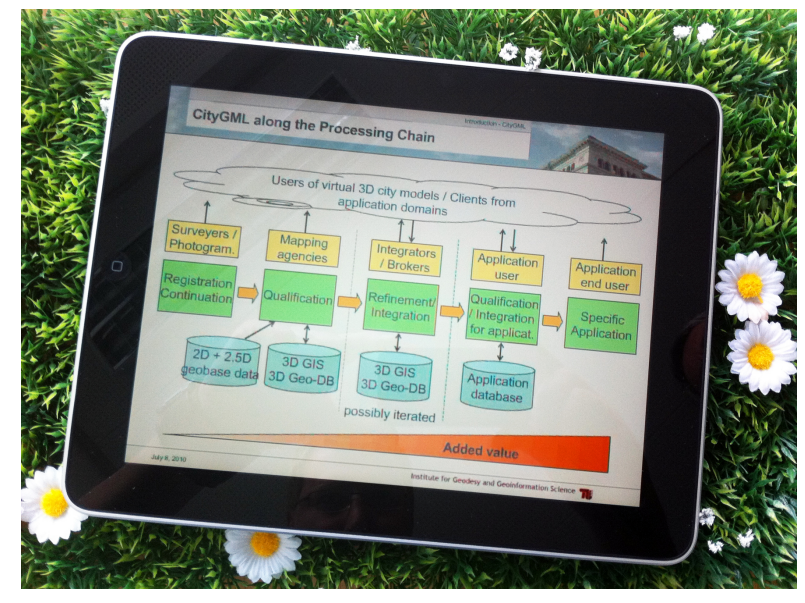

Figure 9: iPad with CityGML podcast

\section{SUMMARY}

This paper has reviewed the activities of the Institute for Geodesy and Geoinformation Science concerning development of learning material on standards in the field of geoinformation modelling, especially urban information modelling, XML, GML, and CityGML. We reviewed our first initiatives in creating e-learning material including lectures-on-demand, exercises, etc. We discussed the drawbacks of our first approach creating material only for desktop computers, with permanent Internet connection, and based on appropriate Adobe Flash formats. Furthermore, we stuck in the problem of sustainability, as our prepared material was already outdated one year after creation, as the standards we have discussed jumped to the next major release.

We developed an approach for creating e-learning material suitable for the most mobile devices and with the opportunity to update our material without substantial work like re-taping hours of lecture videos. We applied Speech-to-Text and Textto-Speech technologies and synchronised the synthetic voice with animated PowerPoint slides. Both are exported as a MP4 video file, which can be published as podcast using a well- 
defined RSS feed. Once one have subscribed to the podcast using the RSS feed, his podcatcher software keeps the user up to date in case of updates.

In fact, to prepare the material for the first time, for example to create the scripts which are needed for the Text-to-Speech software, is more time consuming as simply videotaping a lecture. However, in case of large amount of learning material that is subject to regular changes, the required time for updating the material will be reduced significantly. Furthermore, there is no need of one specific lecturer and environment.

\section{REFERENCES}

Fritsch, D. 2007: Podcasting Photogrammetry - A Contribution to Life-Long Learning. In: Photogrammetric Week '07, (Ed. Fritsch), Wichmann, Heidelberg, pp. 335-344 http://www.ifp.uni-

stuttgart.de/publications/phowo07/index.html

König, G.; Kaden, R.; Kolbe, T. H. 2010: E-Learning Everywhere with Podcasts and Co. - The CityGML Training Course for Mobile Devices. The International Archives of the Photogrammetry, Remote Sensing and Spatial Information Sciences, Vol. XXXVIII-Part 6, 2010.

http://www.isprs.org/proceedings/XXXVIII/part6/papers/Koe nig/2010-Enschede_Koenig-Kaden_paper.pdf

Open Geospatial Consortium Inc. (OGC), 2008: OpenGIS City Geography Markup Language (CityGML) - Encoding Standard.

http://portal.opengeospatial.org/files/?artifact_id=28802

All online documents are accessed on 30. August 2011 